\title{
Crash Tests of Vehicles - Selected Experiments and Analysis
}

\author{
H. Kovandová* \\ Faculty of Transportation Sciences, Department of Security Technologies and Engineering, Czech Technical \\ University in Prague, Czech Republic \\ *Corresponding author: kovandova@fd.cvut.cz
}

\section{J. Krejčí}

Faculty of Engineering, Czech University of Life Sciences Prague, Czech Republic

\section{J. Kovanda}

Faculty of Transportation Sciences, Department of Security Technologies and Engineering, Czech Technical University in Prague, Czech Republic

DOI: 10.2478/v10158-012-0047-7

\begin{abstract}
The university research projects systematically deal with traffic safety, especially passive safety. Several experiments were carried out with the purpose to increase the knowledge in the automotive safety field, to obtain in-deep information from non-standard processes and data for validation of mathematical simulations and to extend the results and knowledge databases.
\end{abstract}

KEY WORDS: Passive safety of vehicles, crash test, deformation, injury, experiment.

\section{INTRODUCTION}

Research of passive safety of all categories of vehicles covers many areas. The partial results from different areas are subsequently synthesized and implemented into vehicle design. The current knowledge of M1 category vehicles is so advanced, that legislatively defined method of verifying barrier testing - the frontal crash test - has been enacted. The conditions under which given test is carried out are firmly established and form the basis for evaluation criteria of vehicle passive safety. Under this method, the test cars are evaluated according to 1975 - ECE Regulation No 33 and 1995 - ECE Regulation No 94. The experimental evaluation is based on biomechanical criteria which determine the severity of possible injuries to human body, represented by dummies.

Since the approval tests are carried out on new vehicles, knowledge databases utilizing information obtained from simulated accidents carried out under non-standard conditions (not identical with legislation, where age of the vehicle influences its parameters) are growing in importance. Monitoring of vehicle structural integrity is an important part of passive safety research, and in case of M1 category vehicles, it is mainly about the strength of integral body and deformation zones. One of the possible ways to assess them is to detect tension at the exposed vehicle body parts. The obtained values can be used to compare the statistics as well as serve as input values in a computer simulation (Kramer, 2008). 
In recent years, several experiments of passenger car collisions with a fixed barrier have been carried out under non-standard conditions. The preparation, process and results of these experiments are the subject of this article.

\section{HEAD-ON COLLISION OF A PASSENGER CAR ŠKODA FABIA 1.2 HTP WITH A BARRIER}

Crash test of a passenger car into fixed barrier was carried out to investigate the restitution parameters of crush zones (Scuderi, 2006).

Further objectives of this experiment were to determine the probability of injuries to driver's head and to find out total instantaneous deformation of the vehicle and consecutive technical condition of the vehicle after the collision.

The vehicle was equipped with the crash test dummy Hybrid II (at driver's position). The dummy was restrained by the three-point safety belt and equipped with a three-axis accelerometer, placed into the head of the dummy. The engine was running at an idle speed. The vehicle was equipped with 8 strain gauge tension sensors and one longitudinal acceleration sensor, as shown at Figure 1. The driving position was equipped with a front airbag, whereas passenger airbag was not installed in this vehicle.
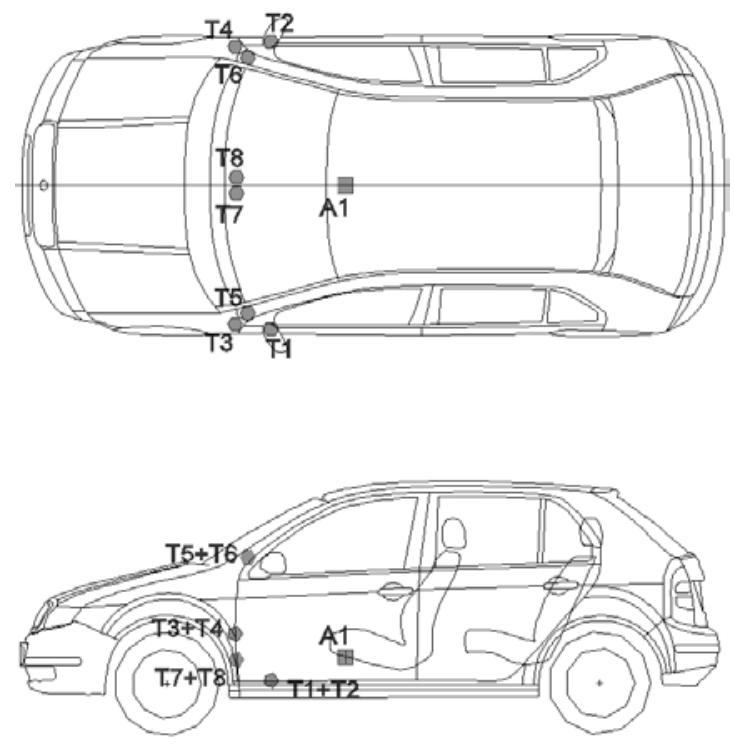

Figure 1: Position of strain gauges T1 - T8 and accelerometer A1 on the vehicle body.

The testing car was accelerated by a special device into a fixed rigid barrier. The weight of the barrier, determined by calculation, amounted to $25 \mathrm{t}$. The weight of the object was $1060 \mathrm{~kg}+72.5 \mathrm{~kg}=1132.5 \mathrm{~kg}$. The velocity of the object at the moment of impact was $50.77 \mathrm{~km} \cdot \mathrm{h}^{-1}$ and its kinetic energy was $112.62 \mathrm{~kJ}$.

After the impact, the following head injury criterion for the crash test dummy Hybrid II was established: $\mathrm{HPC}_{36}=302.94 ; \mathrm{T}_{1}=164.4 \mathrm{~ms}, \mathrm{~T}_{2}=197.8 \mathrm{~ms}$ (Figure 2). 


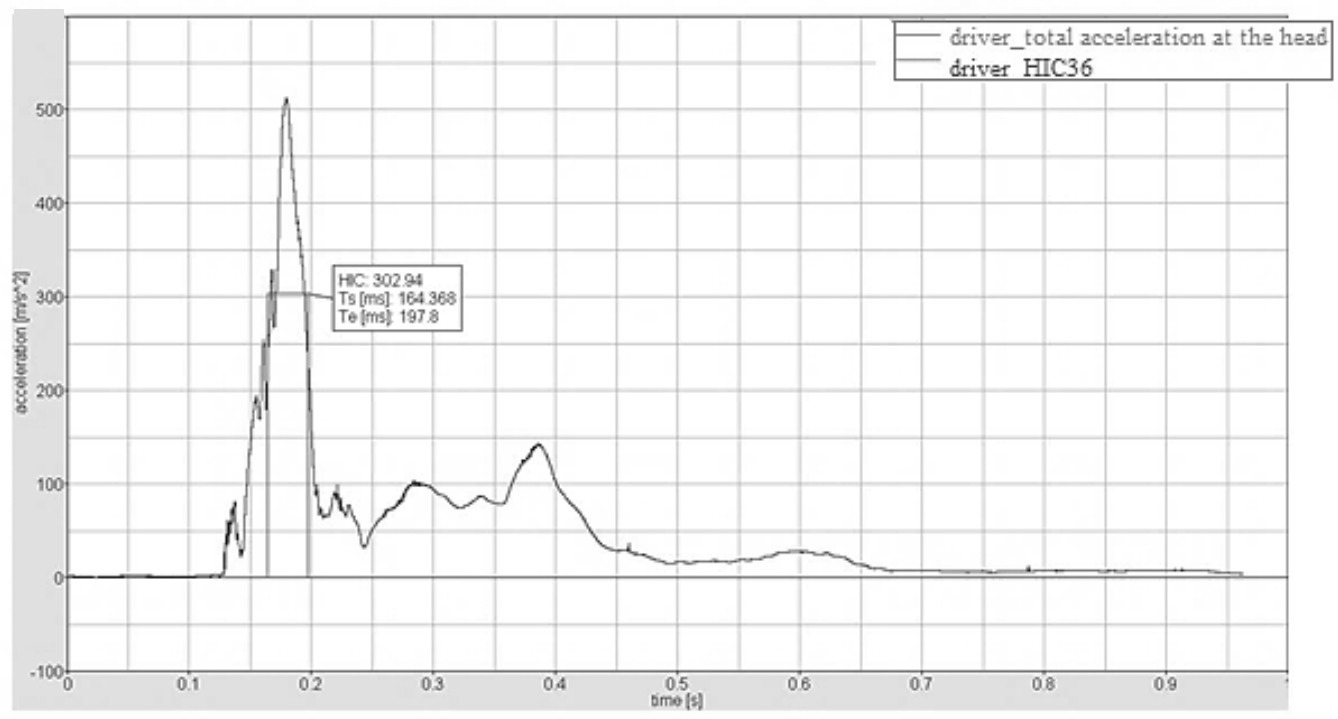

\section{Figure 2: Progress of total acceleration (SAE 1000) at the head of the driver's dummy and injury criteria HIC.}

Total instantaneous vehicle deformation was $0.447 \mathrm{~m}$. Values were obtained from a camera recording with estimated accuracy of $\pm 5 \%$.

\subsection{Condition of the vehicle after collision (visual findings)}

Fluid leaks: coolant leaked, leakage of a small amount of fuel from damaged fuel line to injection units. Brake fluid, engine and gear oil without leaking.

Wheelbase: unchanged - as measured by total station, a deviation of $\pm 2 \mathrm{~mm}$ from original state.

Wheels: tires undamaged - inflated, discs (metal) undamaged.

Passenger space: airbag on the driver's position was activated. Belt pre-tensioners were activated, it was possible to unwind driver's belt, whereas passenger's belt was blocked. The steering wheel remained without visible deformation; displacement of the steering column has not been documented as the steering wheel did not move towards the interior. The position of seats remained unchanged. There was also a visible deformation of the dashboard, specifically in the area of the glove compartment in front of the passenger, where the switch box is towards driver's knees. Asymmetric gaps occurred in plastic parts of the dashboard. Foot pedals remained non-deformed and functional.

Vehicle body: deformation and damage to the hood, headlights and winkers, bumper, bumper beam, left and right front fender, including arches. There was also an occurrence of recesses at the sill of B-pillar connection and cracks in the lower corners of the windshield. Steering remained functional, but the wheel turning angle was limited.

Engine Compartment: left and right longitudinal beams were deformed in the front. The engine moved backwards and the flexible engine mounts on the right side were damaged. Gearbox suspension was deformed on the left side. Damage of radiator including fan, destruction of plastic parts and injection system suction of engine unit were identified. The engine control unit was released from its holder. 


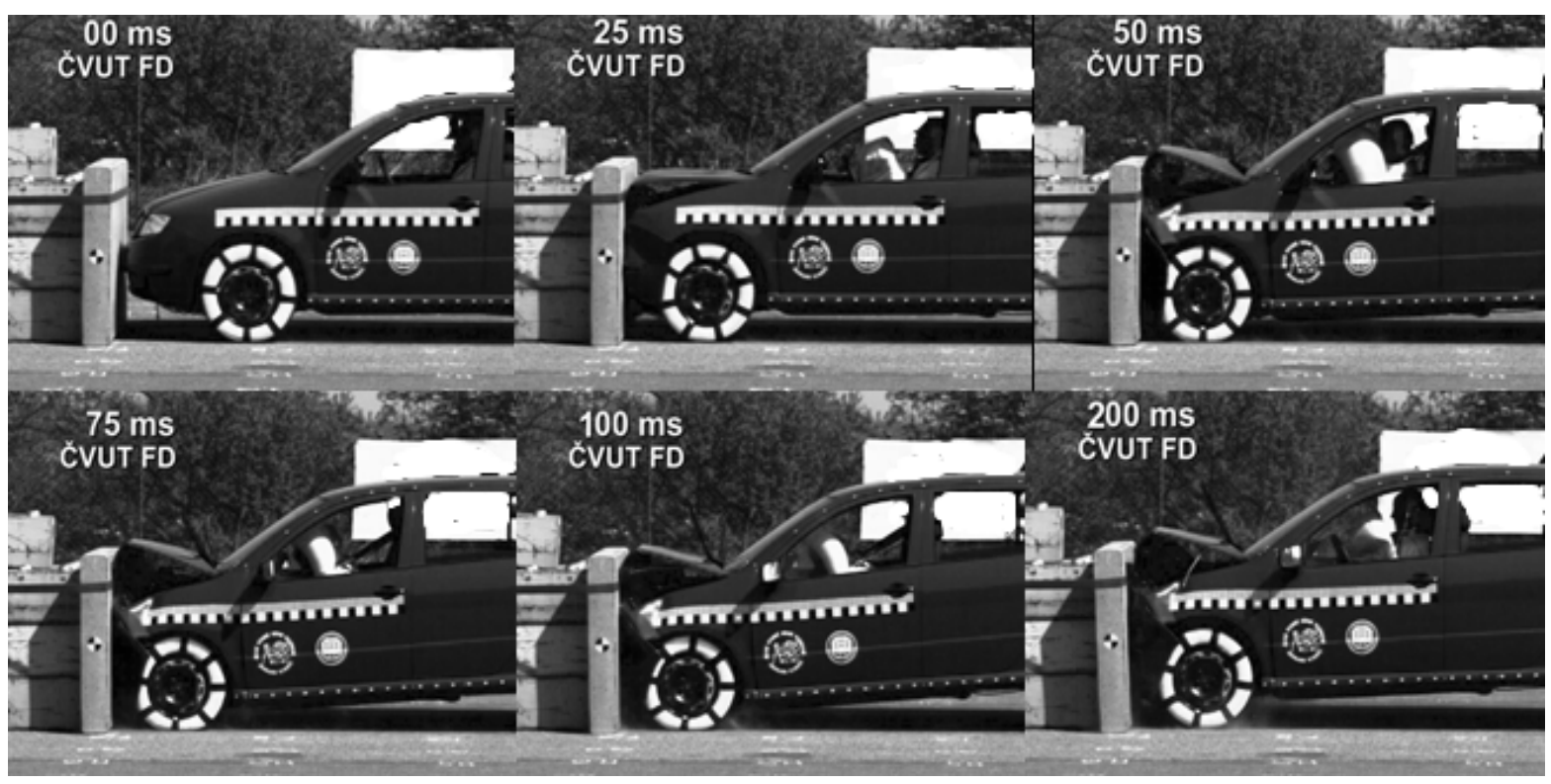

Figure 3: Frontal impact of Škoda Fabia to rigid barrier.

\subsection{Partial conclusion}

After the evaluation of the test, very good safety at the front seats was found. The space for survival remained unchanged. The calculated head injury criterion was far below the threshold limit of 1000 . Probable severity of the injury was at the level of AIS $1-2$, which means skin scrapes, nose fracture, mild concussion (Viano \& Olsen, 2001).

Body strength of Škoda Fabia assessed by deformation in a head-on collision is statistically comparable to cars of a similar concept. The obtained data provided necessary background for restitution analysis using standard mathematical methods.

\section{HEAD-ON COLLISION OF A PASSENGER CAR ŠKODA 120 AND NISSAN MAXIMA WITH A BARRIER}

During the experiment, there were two separate frontal impacts of moving $\mathrm{M}_{1}$ category vehicles with an overlap of $40 \%$ to unmovable rigid barrier. The vehicles differed in the following properties: weight, body condition, degree of corrosion, structure and concepts. The purpose of the tests was to assess the strength of the vehicle body, while establishing dummy acceleration and prediction of injury was not considered.

Both vehicles were equipped with crash test dummies Manikin, both on the driver and passenger seat. The vehicle Škoda 120, manufactured in 1988, was equipped with threepoint seat belts and head restraints. The Nissan Maxima vehicle, manufactured in 1993, was also equipped with three-point seat belts and head restraints and, moreover, a driver side airbag. The corrosion degree of both vehicles corresponded with time of operation under standard conditions.

The same accelerator device and barrier were used as in the previous impact test. The weight of Škoda 120 vehicle with a crew was $875 \mathrm{~kg}+72.5 \mathrm{~kg}+72.5 \mathrm{~kg}=1020 \mathrm{~kg}$, impact velocity $48 \mathrm{~km} \cdot \mathrm{h}^{-1}$ and the degree of vehicle / barrier overlap was $30 \%$. The weight of the Nissan Maxima vehicle with a crew was fixed at $1400 \mathrm{~kg}+72.5 \mathrm{~kg}+72.5 \mathrm{~kg}=1545 \mathrm{~kg}$, impact velocity was $43 \mathrm{~km} \cdot \mathrm{h}^{-1}$ and the degree of vehicle / barrier overlap was $40 \%$. 


\subsection{Condition of Škoda 120 vehicle after collision}

Due to the impact, the front of the car was deformed by $949 \mathrm{~mm}$.

Fluid leaks: Coolant leak from damaged radiator and pipes. Other fluids such as fuel, brake fluid, engine and transmission oil remained without leakage.

Wheelbase: a major shift of front axle - deformation of housing in the vehicle body.

Wheels: tires undamaged - inflated, metal discs undamaged.

Passenger space: blocked unwinding of the seat belt coils and deformed seat belt anchorage points in the body. Large-scale deformation of the left wheel arch and the space for driver's feet (broken by floor). Deformed steering wheel rim as a result of contact with the dummy. Due to the deformation of the partition between the passenger space and the boot (in front) the dashboard frame shifted and subsequently its individual components were twisted. The plastic cover of heating in the space of front passenger's knee was torn after the contact with the dummy. There was also a significant shift in the anchorage of control pedals, pedals themselves were deformed.

Vehicle body: the following parts of the vehicle were deformed and damaged after the impact: the front boot and its suspension, headlights and indicators, front face, bumper, bumper beam, left and right front fender including arches, cracked windshield (partially withdrawn from the frame), left front doors, including rear-view mirror, left sill, breaking of the roof in line of the right A-pillar and left B-pillar, a significant shift of the partition wall between the passenger space and the front boot, change in position and the angle of the grip of the left A-pillar and roof, deformation of front axle, deformation of floor beneath the driver.

Engine Compartment (rear engine): remained without damage.
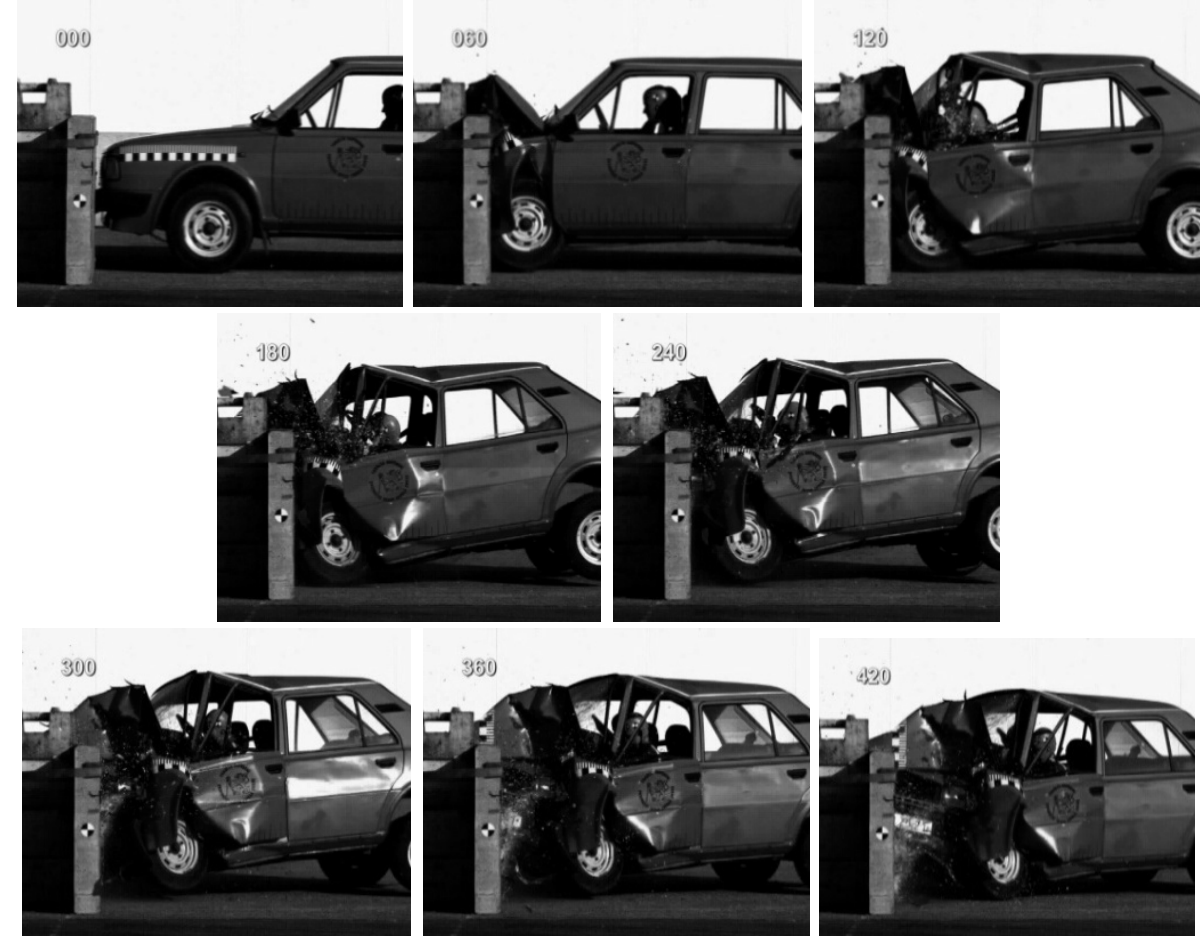

Figure 4: Frontal impact of Škoda 120 with rigid barrier during collision. 


\subsection{Condition of Nissan Maxima after collision}

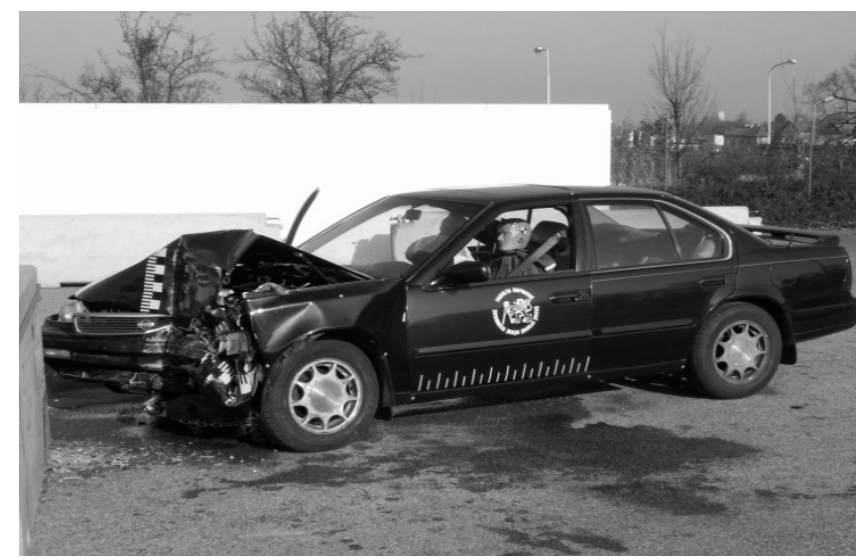

Figure 5: Frontal impact of Nissan Maxima to rigid barrier after collision.

The front part has been deformed by the impact of $400 \mathrm{~mm}$.

Fluid leaks: Coolant leak from damaged radiator and pipelines. Transmission oil leak. Fuel, brake fluid and engine oil did not leak.

Wheelbase: the right side remained without deformation, the left side was reduced by $25 \mathrm{~mm}$.

Wheels: tires undamaged - inflated, alloy wheels undamaged.

Passenger space: activated seat belt pre-tensioners, locked unwinding of seat belt recoils, activated airbag on the driver's side. The vehicle body of the passenger's space not deformed. Deformation of the cover of the glove compartment on the passenger side, and air vents at the right A-pillar on the dashboard released. The position of pedals remained unchanged and pedals were fully functional.

Vehicle body: the following parts of the vehicle were deformed or damaged after the impact: front bonnet and its suspension, headlights and indicators, left fog light, front face, bumper, bumper reinforcement, front left fender including arches. Further damage was visible at the left front wheel suspension, deformation (indentation) in connection with sheet metal roofs left B-pillar. Steering remained functional.

Engine space: deformed left longitudinal beam and the left wheel arch. Damaged radiator including ventilator. Brake booster, operating cylinder or custom brake line were not damaged.

\subsection{Partial conclusion}

The objective of the experiment was to evaluate the safety level of tested vehicles. Škoda 120 , which was approved according to ECE Regulation 12, does not provide sufficient level of passive safety. The car components collapsed and the survival space during the test was unstable. In addition, the vehicle was not equipped with modern passive safety features such as airbags and seat belt pre-tensioners. The test with Nissan Maxima showed significantly better results than the crash test with Škoda 120 . This vehicle was approved by U.S. homologation methodology, which was much stricter than ECE 12. In addition, Nissan Maxima was equipped with effective passive safety components. 


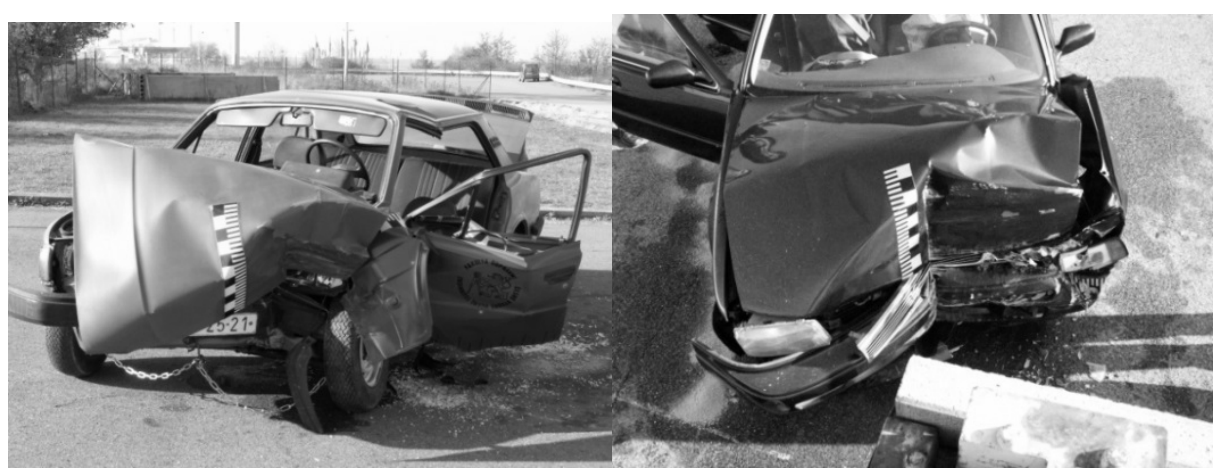

Figure 6: Technical condition of vehicle Škoda 120 (left) and Nissan Maxima (right) after collision.

\section{HEAD-ON COLLISION OF A PASSENGER CAR RENAULT 5 GTD WITH A BARRIER}

A full dynamic passive safety test of a Renault 5 passenger car crash into a fixed barrier was performed to investigate the deformation properties of the given car and dynamics of adult and child dummies. The experiment was carried out on the same test track as the previous tests. It was $\mathrm{M}_{1}$ category vehicle frontal collision with a $40 \%$ overlap to the rigid barrier. The test was supposed to investigate the durability of a body of more than 20-year-old Renault 5 GTD, as well as examine the safety of a crew, which was represented by a dummy Manikin (for the driver) and a P3 dummy (at the rear left side behind the driver), fixed in a child restraint system.

The weight of the vehicle with the crew was $830 \mathrm{~kg}+87 \mathrm{~kg}+15 \mathrm{~kg}+6.6 \mathrm{~kg}=938.6 \mathrm{~kg}$, impact velocity was $52.2 \mathrm{~km} \cdot \mathrm{h}^{-1}$ and the kinetic energy of the object was $98.7 \mathrm{~kJ}$. The same barriers and accelerating equipment were used as in the previous tests.

After the impact, head injury criterion for the dummy Manikin was found at $\mathrm{HPC}_{15}=100$; $\mathrm{HPC}_{36}=136$ (Figure 7). Because the driver's dummy Manikin was equipped with a simple uniaxial accelerometer, the head injury criterion is given for reference purposes and only for basic orientation, without any further evaluation of the severity of possible injuries.

The head injury criterion of the dummy P3 in child restraint system was $\mathrm{HPC}_{15}=492$, $\mathrm{HPC}_{36}=612$ (Figure 8). It correlates with certain head injury and possible cervical spine damage, which was not observed (Dobbertin et al., 2013).

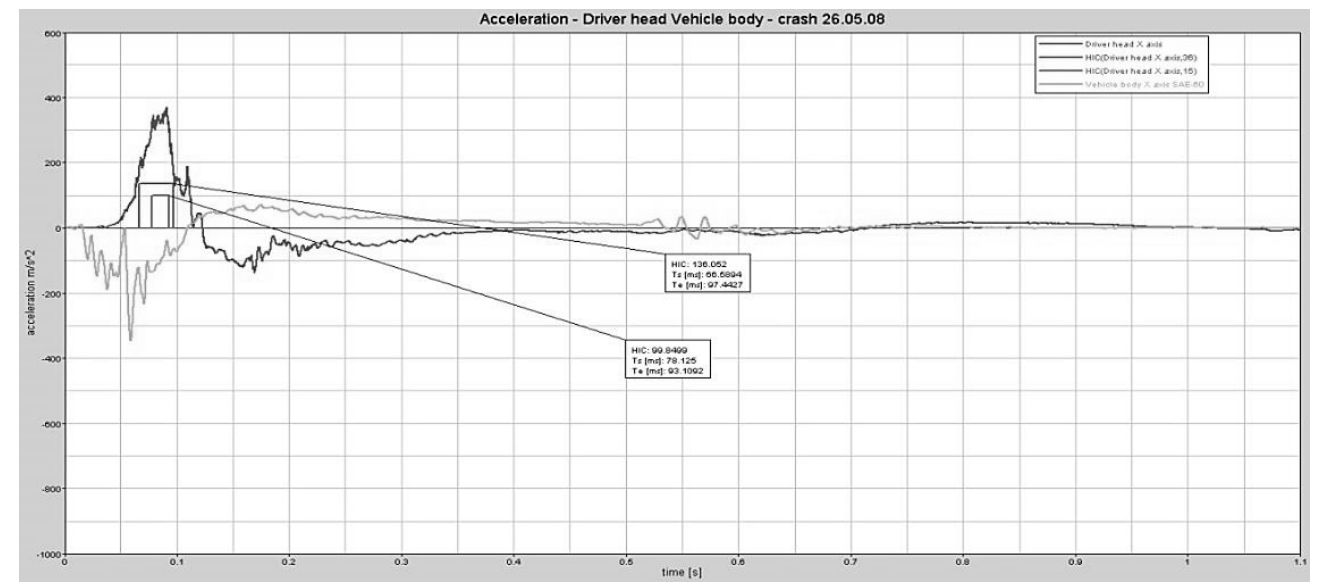

Figure 7: Progress of acceleration (SAE 1000) at the head of the driver's dummy in $x$ direction (dark), head injury criterion HIC and acceleration of the body (SAE 1000) in $x$ direction (light). 


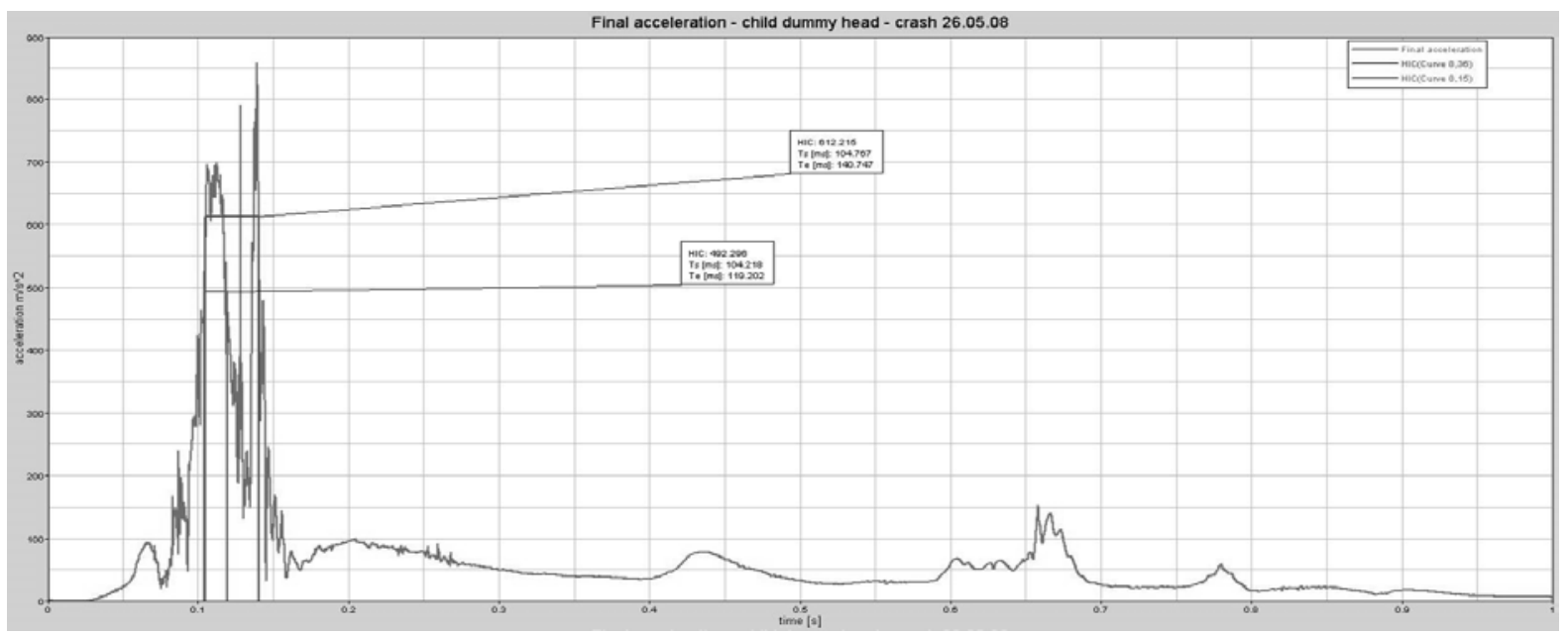

Figure 8: Progress of total acceleration (SAE 1000) in the head of child dummy and head injury criterion HIC.

\subsection{Condition of vehicle after collision (visual findings)}
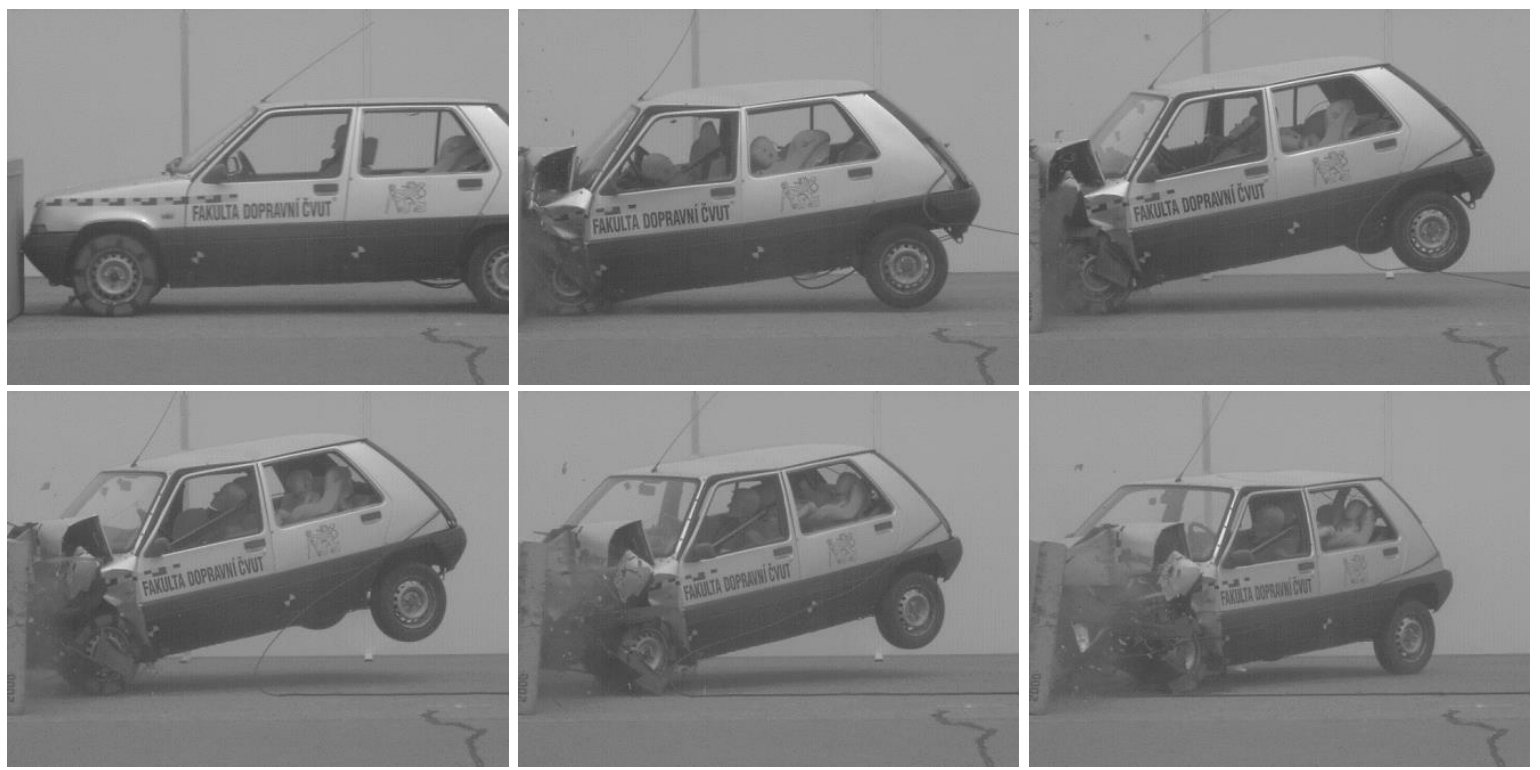

Figure 9: Progress of total acceleration (SAE 1000) in the head of child dummy and head injury criterion HIC.

Fluid leaks: most of the fluids were removed before the test, so, during the test, there was a leak only from oil tanks.

Passenger space: driver's seat belt could be unwind from the coil after collision, both seat belts could be freed of anchor buckles without tools. Seat belts of the child restraint system were fully functional. The records from high-speed camera show vertical and horizontal movements of the steering wheel towards driver and the collision of the rim with the head of the driver's dummy. There was also an overall deformation of the dashboard. The control pedals were also deformed and the floor with a wheel arch on the driver's side was deformed towards the driver's foot space.

Body deformation and damage: bonnet, headlights and indicators, front face, bumper, bumper beam, left and right front fender including arches, sills deformation, "B" pillars, front left door and breaking of the roof. 
Engine compartment: deformed longitudinal beams (left and right). The engine was pushed back as a result of the damaged elastic engine mount. Furthermore, there was a deformed suspension of the gearbox on the left side and a damaged radiator including ventilator. The vehicle was inoperable after the impact.

\subsection{Partial conclusion}

The findings from the experiment above allow to reach a conclusion that the protection of the Renault 5 vehicle's crew in a frontal offset crash into a barrier under given conditions is relatively sufficient when taking into account the age of the vehicle. However, questions remain about the real degree of the child injury. The test results of the child restraint systems fixed by conventional seat belts are usually worse than the test results of child restraint systems which are fixed by ISOFIX system.

\section{RESULTS AND DISCUSSION}

This paper summarizes the experience and knowledge of passive safety of vehicles based on analyses of crash tests carried out the in the past within student projects. The results of the described unique experiments contain a description of passenger cars impacts with a rigid barrier. Specific features are derived from the fact that vehicles of certain age with several years of regular operation were used in realistically simulated real conditions of possible traffic accident scenarios. The majority of standard tests are performed with new vehicles as a part of the homologation process before commissioning. The aim of the described tests was focused on the monitoring of the maximum deceleration of the crash test dummy parts and on the deformation and damage of the car body. Thus, results can be used for the prediction of probable injuries to vehicles crews and for evaluation of technical conditions of damaged vehicles. The basic results prove the fundamental role of legislation in passive safety. Well maintained older vehicles can provide the occupants with sufficient protection level. The realized projects and acquired data are used as important material for student projects and dissertations.

\section{ACKNOWLEDGMENT}

The projects were supported by the grants of Ministry of Transportation of the Czech Republic, grant of Ministry of Industry and Trade FT-TA/024, Technology Agency of the Czech republic TE01020020 and IGA grant of Czech University of Life Sciences 2013:31150/1312/3111.

\section{REFERENCES}

Dobbertin, K. M., Freeman, M. D., Lambert, W. E., Lasarev, M. R., Kohles, S. S., 2013. The relationship between vehicle roof crush and head, neck and spine injury in rollover crashes. Accident Analysis \& Prevention, 58, pp. 46-52.

ECE Regulation No 33 Uniform provisions concerning the approval of vehicles with regard to the behavior of the structure of the impacted vehicles in a head-on collision. 
ECE Regulation No 94 Uniform provisions concerning the approval of vehicles with regard to the protection of the occupants in the event of a frontal collision.

Kovanda, J., First, J., Kovandová, H., Schejbalová, Z., Šotola, M., 2008. VYZ616.005/08 Kolize automobil - bariera III. Praha: ČVUT FD. (in Czech)

Kramer, F., 2008. Passive Sicherheit von Kraftfahrzeugen. Biomechanik - Simulation Sicherheit im Entwicklungsprozess, 3. überarbeitete Auflage. Dresden: Praxis ATZ/MTZFachbuch. ISBN 978-3-8348-0536-2.

Prasad, P., Mertz, H., 1985. The position of the United States Delegation to the ISO working group 6 on the use of HIC in the Automotive Environment. SAE Technical Paper Series.

Schmitt, K. U., Niederer, P. F., Muser, M. H., Walz, F., 2007. Trauma Biomechanics, Accidental Injury in Traffic and Sport. Berlin: Springer-Verlag. ISBN 978-3-540-73872-5.

Scuderi, F., 2006. Analysis and implementation of restitution coefficient in a high-speed frontend crash test of Skoda Fabia 1.2 HP. Diploma thesis n. 37782. Universita degli Study di Bergamo, Italy.

Viano, D. C., Olsen, S., 2001. The effectiveness of active head restraint in preventing whiplash. J Trauma, 51 (5), pp. 959-969. 